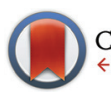

CrossMark \& click for updates

Cite this: Polym. Chem., 2017, 8, 414

\title{
Self-reporting dynamic covalent polycarbonate networks $\uparrow$
}

\author{
Alexander M. Schenzel, ${ }^{a, b}$ Norbert Moszner ${ }^{c}$ and Christopher Barner-Kowollikª,b,d
}

Here, we report the first-time development of polycarbonate networks with self-reporting thermoreversible bonding/debonding on demand properties. The reversible linkages within the network are based on a Hetero-Diels-Alder (HDA) moiety, which is able to undergo cleavage and rebonding as a function of temperature within minutes. As HDA pair a phosphoryl dithioester and a cyclopentadiene moiety are employed as bonding and debonding take place in the temperature range between $25-120{ }^{\circ} \mathrm{C}$. The degradation and rebonding can be readily traced by visible inspection due to the self-reporting nature of the HDA moiety. In order to prove the reversibility, linear polycarbonates $\left(M_{\mathrm{w}}=4.200-20.000 \mathrm{~g} \mathrm{~mol}^{-1}\right)$ including the reversible linkage in each repeating unit were generated and carefully analyzed using size exclusion chromatography (SEC), UV/Vis analysis and high temperature ${ }^{1} \mathrm{H}$ NMR spectroscopy. Subsequently, polycarbonate networks bearing HDA units - allowing the networks to be fully degraded into small molecules - were synthesized, debonded and bonded several times in the temperature range between 25 and $120^{\circ} \mathrm{C}$ within minutes. The present study thus introduces fully degradable polycarbonate networks based on a facile chemical concept as a viable alternative to networks based on $\mathrm{C}-\mathrm{C}$ bond formation that disallow a complete degradation.

Received 19th October 2016

Accepted 14th November 2016

DOI: $10.1039 / \mathrm{c} 6$ py01840h

www.rsc.org/polymers

\section{Introduction}

The design of bonding/debonding on demand polymeric materials that are able to change their physical properties rapidly in a cyclic fashion due to an external trigger is a highly investigated subject in materials science. ${ }^{1-4}$ In general, triggers such as light, ${ }^{5-7}$ heat, ${ }^{8,9} \mathrm{pH}$ changes, ${ }^{10,11}$ or an acid/base reaction $^{12-14}$ can be employed to alter polymeric structures. Within the field of reversible degradable polymeric materials, the investigation of reversible covalent bonds within a polymeric network is of key interest today, as it allows the most drastic changes in the polymer properties. ${ }^{15}$ Within this context, a broad range of chemical concepts have been investigated, such as photoreversible olefin cycloadditions, ${ }^{16}$ carbene dimerization, ${ }^{17}$ sulfide coupling $^{18}$ and thermally cleavable

\footnotetext{
${ }^{a}$ Preparative Macromolecular Chemistry, Institut für Technische Chemie und Polymerchemie, Karlsruhe Institute of Technology (KIT), Engesserstr. 18, 76128 Karlsruhe, Germany

${ }^{b}$ Institut für Biologische Grenzflächen, Karlsruhe Institute of Technology (KIT), Hermann-von-Helmholtz-Platz 1, 76344 Eggenstein-Leopoldshafen, Germany. E-mail: christopher.barner-kowollik@kit.edu

${ }^{c}$ Ivoclar Vivadent AG, Bendererstr. 2, FL-9494 Schaan, Liechtenstein

${ }^{d}$ School of Chemistry, Physics and Mechanical Engineering, Queensland University of Technology (QUT), 2 George St, OLD 4000 Brisbane, Australia.

E-mail: christopher.barnerkowollik@qut.edu.au

$\dagger$ Electronic supplementary information (ESI) available. See DOI: 10.1039/ c6py01840h
}

alkoxyamines. ${ }^{19}$ Thereby, Diels-Alder (DA) and Hetero-DielsAlder (HDA) chemistry are highly interesting and by far the most widely investigated reversible linkage mechanisms. This is due to the availability of a broad variety of dienes and dienophiles that can potentially be utilized, allowing the fine-tuning of the temperature range in which the bonding and debonding takes place. ${ }^{20-24}$ Furthermore, not only the chemical structure of the diene and ene can be employed to adjust the equilibrium position (and thus the bonding/debonding temperatures), yet also the location of the linkage within the macromolecular chain as well as the persistence length and chain length of the macromolecular segments to either side of the linkage can critically influence - on the basis of entropic effects - the debonding temperatures. ${ }^{25,26}$

A closer look at the origin of reversibly degradable materials indicates that chain- and step-growth based polymers show drastically different abilities in terms of their degradability (and reversibility). Specifically, in polymers formed via a free radical polymerization (FRP), the stimuli-responsive moiety cannot be incorporated into the $\mathrm{C}-\mathrm{C}$ based lateral chain of the polymer. Therefore, FRP based polymer networks can only be degraded into linear polymers, as only the crosslinks between the polymeric chains can bear the reversibly degradable moiety. ${ }^{27}$ In contrast, step-growth based polymers can be designed to contain a responsive moiety within every repeating unit, resulting in the possibility to degrade the polymer into small molecules. Therefore, the change in physical properties 
of the polymer can be increased significantly compared to a FRP based bonding/debonding on demand network. ${ }^{28}$ As polycarbonates constitute a vital part of the polymers produced via step-growth polymerization (4.4 Mio. $\mathrm{t}$ in 2016), ${ }^{29}$ today, polycarbonates with bonding/debonding abilities are of major interest. Critically, however, only polycarbonates bearing a stimuli-responsive end group or side-chain functionality are known in literature, with fully degradable polycarbonate networks being virtually absent. ${ }^{30-33}$

The current study seeks to fill this critical gap by introducing polycarbonate based cross-linked materials bearing the reversible linkage within every repeating unit, allowing degradation to the small molecule level, and therefore resulting in drastic changes in the physical properties of the network. The reversibility is based on a temperature dependent equilibrium of a HDA system that can be cleaved and rebonded in a certain temperature range. The employed phosphoryl dithioester cyclopentadiene pair was chosen as it shows bonding/debonding behavior between 30 and $140{ }^{\circ} \mathrm{C}$ within minutes resulting in a rapid change of the material properties under relatively mild conditions. As bisphenol A based polycarbonates can only be degraded irreversibly at temperatures above $480{ }^{\circ} \mathrm{C},{ }^{34}$ the developed material represents a significant advance over the state of the art, making the system interesting for several fields of applications, such as medical technology, where the material properties of polycarbonates need to be drastically adjusted in response to an external trigger signal.

\section{Experimental section}

\section{Materials}

1,3,5-Benzenetricarbonyl trichloride (98\%, Sigma Aldrich), 1,5,7-triazabicyclo[4.4.0]dec-5-ene (TBD, 98\%, Alfa Aesar), 3-bromo-1-propanol (97\%, Alfa Aesar), 4-bromobutyryl chloride (97\%, Alfa Aesar), cyclopentadienyl sodium (NaCp, 2.0 M in THF, Sigma Aldrich), dichloromethane (DCM, 99.8\%, dry, Acros), dimethyl carbonate (DMC, 99\%, Sigma Aldrich), ethyl acetate (EA, 98\%, VWR), ethylene glycol (99\%, Sigma Aldrich), $\mathrm{N}, \mathrm{N}$-dimethylformamide (DMF, 99\%, Merck), $n$-hexane (98\%, VWR), oxalyl chloride (98\%, Sigma Aldrich), phosgene (15 wt\% solution in toluene, Sigma Aldrich), pyridine (anhydrous, 99.8\%, Sigma Aldrich), tetrahydrofuran (THF, 99.5\%, Acros), triethylamine ( $\geq 99 \%$, Sigma Aldrich) and zinc chloride ( $\geq 98 \%$, Sigma Aldrich) were used as received. 4-((((Diethoxyphosphoryl)carbonothioyl)thio)methyl)benzoic acid (PDT) and 1,10-di(cyclopentadienyl)decane (DiCp-linker) were synthesized according to a previous publication. ${ }^{27}$

\section{Synthesis of the HDA containing diol (HDA-diol)}

In order to prepare a HDA-containing polycarbonate, a diol bearing two HDA moieties had to be synthesized in a previous step. Hence, $1.0 \mathrm{~g}$ of PDT (1.0 eq., $2.87 \mathrm{mmol}$ ) was dissolved in $20 \mathrm{ml}$ of dry DCM. After the addition of $0.1 \mathrm{~mL}$ dry DMF, $0.27 \mathrm{~mL}$ of oxalyl chloride (1.1 eq., $3.16 \mathrm{mmol}, 400 \mathrm{mg}$ ) were added dropwise and the reaction mixture was stirred for $2 \mathrm{~h}$ at ambient temperature. After removal of the solvent, $20 \mathrm{~mL}$ ethylene glycol were added and the solution was heated to $60{ }^{\circ} \mathrm{C}$ for $16 \mathrm{~h}$. DCM was added and the organic phase was washed with water, $\mathrm{NaHCO}_{3}$ solution and brine. The solvent was removed and the crude product was purified via column chromatography (cyclohexane/EA 1/1) to yield a purple liquid of PDT-OH (740 mg, 70\% yield). ${ }^{1} \mathrm{H}$ NMR $(400 \mathrm{MHz}$, $\left.\mathrm{CDCl}_{3}, \delta, \mathrm{ppm}\right): 1.34\left(\mathrm{t}, 6 \mathrm{H}, \mathrm{OCH}_{2} \mathrm{CH}_{3}\right), 3.88-3.95(\mathrm{~m}, 2 \mathrm{H}$, $\left.\mathrm{OCH}_{2} \mathrm{CH}_{2} \mathrm{OH}\right), 4.17-4.32\left(\mathrm{~m}, 4 \mathrm{H}, \mathrm{OCH}_{2} \mathrm{CH}_{3}\right), 4.38-4.45(\mathrm{~m}, 2 \mathrm{H}$, $\mathrm{OCH}_{2} \mathrm{CH}_{2} \mathrm{OH}$ ), 4.48 (s, 2H, $\mathrm{SCH}_{2}$ ), 7.35 (d, 2H, ArH), 7.98 (d, $2 \mathrm{H}, \mathrm{ArH})$.

$1.0 \mathrm{~g}$ of PDT-OH (2.0 eq., $2.66 \mathrm{mmol}$ ), $360 \mathrm{mg}$ of DiCplinker (1.0 eq., $1.33 \mathrm{mmol}$ ) and $20 \mathrm{mg} \mathrm{ZnCl}_{2}$ (0.1 eq., $0.13 \mathrm{mmol}$ ) were dissolved in $20 \mathrm{~mL}$ EA and stirred for 20 minutes. After washing with water, the solvent was removed to yield the HDA-diol as a colorless and highly viscous liquid (1.35 g, 99\%). ${ }^{1} \mathrm{H}$ NMR (400 MHz, DMSO- $d_{6}, \delta$, ppm): 1.12-1.35 $\left(\mathrm{m}, 24 \mathrm{H}, \mathrm{OCH}_{2} \mathrm{CH}_{3}, \mathrm{C}_{\mathrm{HDA}} \mathrm{CH}_{2} \mathrm{CH}_{2}\left(\mathrm{CH}_{2}\right)_{3}\right), 1.37-1.58(\mathrm{~m}, 4 \mathrm{H}$, $\left.\mathrm{C}_{\mathrm{HDA}} \mathrm{CH}_{2} \mathrm{CH}_{2}\left(\mathrm{CH}_{2}\right)_{3}\right)$ 1.65-1.99 (m, 4H, $\left.\mathrm{C}_{\mathrm{HDA}} \mathrm{CH}_{2} \mathrm{CH}_{2}\left(\mathrm{CH}_{2}\right)_{3}\right)$, 2.09-2.41 (m, 4H, $\left.\mathrm{CH}_{2, \mathrm{HDA}-\text { bridge }}\right), 3.32-3.43\left(\mathrm{~m}, 2 \mathrm{H}, \mathrm{CH}_{\mathrm{HDA}}\right)$, 3.65-3.73 (m, 4H, $\mathrm{SCH}_{2} \mathrm{C}_{\mathrm{ar}}$ ), 4.02-4.23 (m, 4H, $\left.\mathrm{OCH}_{2} \mathrm{CH}_{2} \mathrm{OH}\right)$, 4.24-4.33 (m, 8H, $\left.\mathrm{OCH}_{2} \mathrm{CH}_{3}\right), 4.39-4.50\left(\mathrm{~m}, 4 \mathrm{H}, \mathrm{OCH}_{2} \mathrm{CH}_{2} \mathrm{OH}\right)$, 5.43-6.42 (m, 4H, CH HDA-Db.) 7.50 (d, 4H, ArH), 7.93 (d, 4H, ArH). ESI-MS $\left(+\mathrm{Na}^{+}\right): \quad m / z$ calculated 1077.3274, found 1077.3289.

\section{Synthesis of HDA containing linear polycarbonates (DiHDA-PC)}

Different ratios of the HDA-diol and phosgene (15 wt\% in toluene, ratios between $1.00: 1.00$ for $\mathbf{P 4}$, to $1.00: 0.90$ for $\mathbf{P 1})$ were dissolved in dry DCM. Dry pyridine (2.0 eq. compared to diol) was added and the reaction mixture was stirred at ambient temperature for $6 \mathrm{~h}$. Subsequently, the polymer was precipitated in $n$-hexane and dried under reduced pressure. ${ }^{1} \mathrm{H}$ NMR (400 MHz, DMSO- $d_{6}, \delta, \mathrm{ppm}$ ): 1.10-1.38 (m, $\mathrm{OCH}_{2} \mathrm{CH}_{3}$, $\left.\mathrm{C}_{\mathrm{HDA}} \mathrm{CH}_{2} \mathrm{CH}_{2}\left(\mathrm{CH}_{2}\right)_{3}\right), \quad 1.38-1.60 \quad\left(\mathrm{~m}, \quad \mathrm{C}_{\mathrm{HDA}} \mathrm{CH}_{2} \mathrm{CH}_{2}\left(\mathrm{CH}_{2}\right)_{3}\right)$

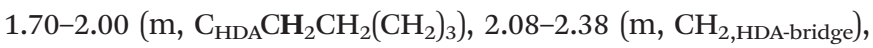
3.38-3.45 (m, $\left.\mathrm{CH}_{\mathrm{HDA}}\right), 3.65-3.75\left(\mathrm{~m}, \mathrm{SCH}_{2} \mathrm{C}_{\mathrm{ar}}\right), 3.88-4.01(\mathrm{~m}$, $\left.\mathrm{OCH}_{2} \mathrm{CH}_{2} \mathrm{OH}\right), \quad 4.02-4.23\left(\mathrm{~m}, \mathrm{OCH}_{2} \mathrm{CH}_{3}\right), 4.32-4.33$ (m, $\left.\mathrm{OCH}_{2} \mathrm{CH}_{2} \mathrm{OC}(\mathrm{O})\right), \quad 4.40-4.50\left(\mathrm{~m}, \quad \mathrm{OCH}_{2} \mathrm{CH}_{2} \mathrm{OH}\right), 4.92$ (t, $\mathrm{OCH}_{2} \mathrm{CH}_{2} \mathrm{OC}(\mathrm{O})$ ) 5.43-6.42 (m, $\mathrm{CH}_{\text {HDA-Db. }}$ ), 7.50 (d, ArH), 7.93 (d, ArH). Detailed SEC analysis of the polycarbonates P1-P4 can be found in the ESI. $\dagger$

\section{Synthesis of the HDA containing triol (HDA-triol)}

In order to synthesize a HDA-containing polymer network that can be degraded into small molecules, a triol bearing three HDA units had to be prepared beforehand. Therefore, $6.5 \mathrm{~mL}$ 3-bromo-1-propanol (4 eq., $72 \mathrm{mmol}, 10 \mathrm{~g}$ ) were dissolved in dry DCM at $0{ }^{\circ} \mathrm{C} .10 \mathrm{ml}$ triethylamine (4 eq., $72 \mathrm{mmol}, 7.2 \mathrm{~g}$ ) were added and the solution was stirred at $0{ }^{\circ} \mathrm{C}$ for 30 minutes. Next, a solution of $4.8 \mathrm{~g}$ 1,3,5-benzenetricarbonyl trichloride (1.0 eq., $18 \mathrm{mmol}$ ) in $20 \mathrm{~mL}$ dry DCM was added dropwise. The solution was stirred at $0{ }^{\circ} \mathrm{C}$ for $2 \mathrm{~h}$ and sub- 
sequently at ambient temperature for $16 \mathrm{~h}$. The white precipitant was filtered off and the solution was washed with $\mathrm{NaHCO}_{3}$ solution and brine. After removing the solvent, the crude product was purified via column chromatography (cyclohexane/EA 3/1) to yield the TriBr-linker as a white solid (6.3 g, $62 \%$ yield). ${ }^{1} \mathrm{H}$ NMR (400 MHz, $\mathrm{CDCl}_{3}, \delta, \mathrm{ppm}$ ): 2.37 (dt, $6 \mathrm{H}$, $\left.\mathrm{CH}_{2} \mathrm{BrCH}_{2} \mathrm{CH}_{2} \mathrm{O}\right), 3.56\left(\mathrm{t}, 6 \mathrm{H}, \mathrm{CH}_{2} \mathrm{BrCH}_{2} \mathrm{CH}_{2} \mathrm{O}\right), 4.54(\mathrm{t}, 6 \mathrm{H}$, $\left.\mathrm{CH}_{2} \mathrm{BrCH}_{2} \mathrm{CH}_{2} \mathrm{O}\right), 8.84$ (s, $3 \mathrm{H}, \mathrm{H}_{\mathrm{ar}}$ ).

To a solution of $10.5 \mathrm{~mL}$ of a $2 \mathrm{M} \mathrm{NaCp}$ solution in THF (6.0 eq., $21 \mathrm{mmol}$ ) in $30 \mathrm{~mL}$ dry THF, a solution of $2.0 \mathrm{~g}$ TriBrlinker (1.0 eq., $3.5 \mathrm{mmol}$ ) in $30 \mathrm{~mL}$ dry THF was added dropwise at $0{ }^{\circ} \mathrm{C}$. After stirring for $1 \mathrm{~h}$ at $0{ }^{\circ} \mathrm{C}$, the reaction mixture was filtered over silica gel using $200 \mathrm{~mL}$ EA. After removal of the solvent the crude product was purified via column chromatography (cyclohexane/EA 6/1) to yield the TriCp-linker as a yellow liquid (430 mg, 25\% yield). ${ }^{1} \mathrm{H} \mathrm{NMR} \mathrm{(400} \mathrm{MHz}, \mathrm{CDCl}_{3}$, $\delta$, ppm): 2.08 (dt, 6H, $\left.\mathrm{CH}_{2} \mathrm{BrCH}_{2} \mathrm{CH}_{2} \mathrm{O}\right), 2.55$ (t, 6H, $\left.\mathrm{CH}_{2} \mathrm{BrCH}_{2} \mathrm{CH}_{2} \mathrm{O}\right), 2.96$ (d, 6H, $\left.\mathrm{CH}_{2 \mathrm{Cp}}\right), 4.42$ (t, 6H, $\mathrm{CH}_{2} \mathrm{BrCH}_{2} \mathrm{CH}_{2} \mathrm{O}$ ), 6.05-6.46 (m, 9H, $\mathrm{CH}_{\mathrm{Cp}}$ ), 8.84 (s, 3H, $\mathrm{H}_{\mathrm{ar} .}$ ).

$430 \mathrm{mg}$ TriCp-linker (1.0 eq., $0.8 \mathrm{mmol}$ ) were directly added to a solution of $950 \mathrm{mg}$ PDT-OH (3.0 eq., $2.4 \mathrm{mmol}$ ) and $2 \mathrm{mg}$ $\mathrm{ZnCl}_{2}$ (0.1 eq., $0.08 \mathrm{mmol}$ ) in DCM to prevent dimerization of the $\mathrm{Cp}$ moieties. The solution was stirred for 20 minutes at ambient temperature. After washing with water, the solvent was removed to yield the HDA-triol as a white solid (1.36 g, 99\% yield). ${ }^{1} \mathrm{H}$ NMR (400 $\left.\mathrm{MHz}, \mathrm{CDCl}_{3}, \delta, \mathrm{ppm}\right): 1.15-1.43(\mathrm{~m}$, $\left.18 \mathrm{H}, \mathrm{OCH}_{2} \mathrm{CH}_{3}\right), \quad 1.60-1.89\left(\mathrm{~m}, 6 \mathrm{H}, \mathrm{C}_{\mathrm{HDA}} \mathrm{CH}_{2} \mathrm{CH}_{2} \mathrm{CH}_{2} \mathrm{O}\right)$, 1.90-2.11 (m, 6H, $\left.\mathrm{C}_{\mathrm{HDA}} \mathrm{CH}_{2} \mathrm{CH}_{2} \mathrm{CH}_{2} \mathrm{O}\right), 2.15-2.45(\mathrm{~m}, 6 \mathrm{H}$, $\mathrm{CH}_{2, \mathrm{HDA} \text {-bridge }}$ ), 3.01-3.34 (m, 3H, $\left.\mathrm{CH}_{\mathrm{HDA}}\right), 3.35-3.52$ (m, $6 \mathrm{H}, \mathrm{SCH}_{2} \mathrm{C}_{\mathrm{ar}}$ ), 3.85-4.00 (m, 6H, $\left.\mathrm{OCH}_{2} \mathrm{CH}_{2} \mathrm{OH}\right), 4.01-4.25$ $\left(\mathrm{m}, 12 \mathrm{H}, \mathrm{OCH}_{2} \mathrm{CH}_{3}\right), 4.26-4.54\left(\mathrm{~m}, 12 \mathrm{H}, \mathrm{OCH}_{2} \mathrm{CH}_{2} \mathrm{OH}\right.$, $\mathrm{C}_{\mathrm{HDA}} \mathrm{CH}_{2} \mathrm{CH}_{2} \mathrm{CH}_{2} \mathrm{O}$ ), 5.56-6.46 (m, 6H, $\left.\mathrm{CH}_{\mathrm{HDA}-\mathrm{Db} .}\right) 7.50$ (d, 6H, $\mathrm{ArH}), 7.93$ (d, 6H, ArH), 8.84 (s, 3H, Har.). ESI-MS $\left(+\mathrm{Na}^{+}\right): m / \mathrm{z}$ calculated 1727.3956, found 1727.4114 .

\section{Synthesis of the HDA-containing polycarbonate network} (TriHDA-PC)

$2.0 \mathrm{~g}$ HDA-triol (2.0 eq., $1.2 \mathrm{mmol}$ ) and $0.15 \mathrm{~mL}$ dimethyl carbonate (3.0 eq., $1.8 \mathrm{mmol}, 160 \mathrm{mg}$ ) were dissolved in $2 \mathrm{~mL}$ of DCM. $1.5 \mathrm{mg}$ TBD (0.02 eq., $0.01 \mathrm{mmol}$ ) was added and the reaction mixture was heated to $35{ }^{\circ} \mathrm{C}$ for $24 \mathrm{~h}$. The formed network was dried under reduced pressure.

\section{Characterization}

${ }^{\mathbf{1}}$ H NMR spectroscopy. ${ }^{1} \mathrm{H}$ NMR spectroscopy was carried out on a Bruker Advance III 400 spectrometer with a CryoProbe at $400 \mathrm{MHz}$ in $\mathrm{CDCl}_{3}$ or DMSO- $d_{6}$ with 16 scans for standard measurements and in DMSO- $d_{6}$ with 128 scans for the linear polymers.

UV-visible spectroscopy. UV-visible spectroscopy was performed using a Cary 300 Bio spectrophotometer (Varian) featuring a thermostated sample cell holder. Absorption spectra of the samples were recorded with a resolution of $1 \mathrm{~nm}$ and a slit width of $2 \mathrm{~nm}$ in a quartz glass cuvette (VWR, quartz glass SUPRASIL®). The absorption at $530 \mathrm{~nm}$ was measured in DMF (concentration: $10 \mathrm{mg} \mathrm{mL}^{-1}$ ) at temperatures ranging from 20 to $100{ }^{\circ} \mathrm{C}$ (upper limit of the instrument), with a heating/ cooling rate of $5^{\circ} \mathrm{C} \mathrm{min}^{-1}$.

Size exclusion chromatography (SEC). Size Exclusion Chromatography (SEC) measurements were performed on a Polymer Laboratories (Varian) PL-GPC 50 Plus Integrated System, comprising an autosampler, a PLgel $5 \mathrm{~mm}$ bead-size guard column $(50 \times 7.5 \mathrm{~mm})$, one PLgel $5 \mathrm{~mm}$ Mixed E column $(300 \times 7.5 \mathrm{~mm})$, three PLgel $5 \mathrm{~mm}$ Mixed $\mathrm{C}$ columns $(300 \times 7.5 \mathrm{~mm})$ and a differential refractive index detector using THF as the eluent at $35{ }^{\circ} \mathrm{C}$ with a flow rate of $1 \mathrm{~mL}$ $\mathrm{min}^{-1}$. The GPC system was calibrated using linear poly (styrene) standards ranging from 476 to $2.5 \times 10^{6} \mathrm{~g} \mathrm{~mol}^{-1}$ and linear poly(methyl methacrylate) standards ranging from 700 to $2 \times 10^{6} \mathrm{~g} \mathrm{~mol}^{-1}$. The resulting molar mass distributions were determined by universal calibration using MarkHouwink parameters for PMMA $\left(K=0.000128 \mathrm{dL} \mathrm{g}^{-1}, \alpha=\right.$ $0.69) .^{35}$

\section{Results and discussion}

The aim of the study was to prepare a polymer network based on a step-growth polymerization process that can reversibly be cleaved and rebonded multiple times. In contrast to a radical polymerization, a polyaddition or -condensation reaction has the advantage that the reversible linkage can be incorporated into the backbone of the polymer, allowing the network to be degraded into small molecules instead of merely linear polymeric chains (Scheme 1). As reversible linkage, a HDA moiety was selected. To ensure a fast cleavage and reformation under

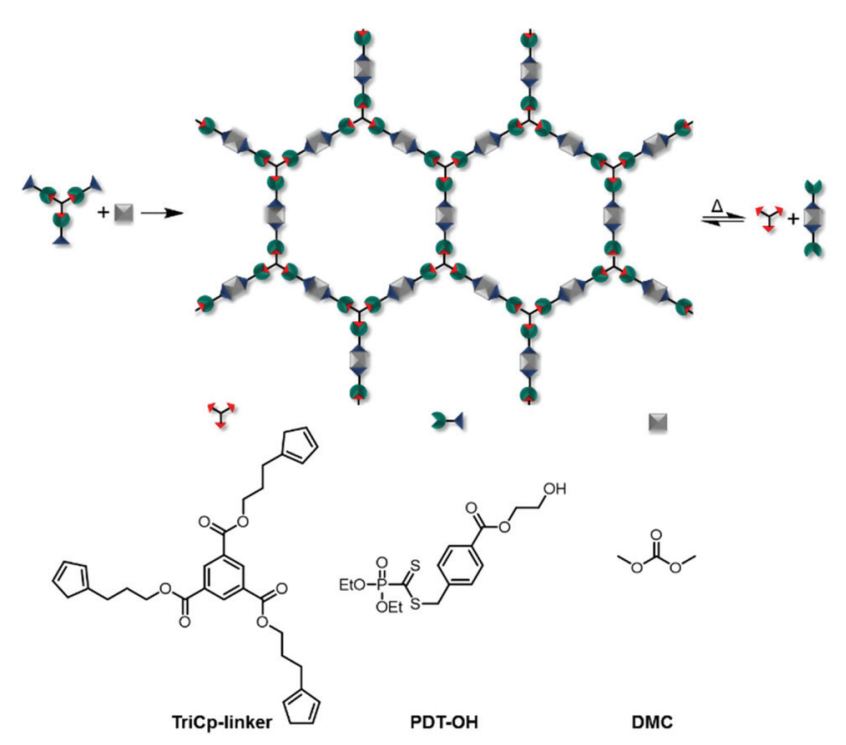

Scheme 1 General concept of the bonding/debonding on demand polycarbonate. The network is formed via the reaction of a triol species (HDA-triol) - which is formed via an HDA reaction of the TriCp-linker and PDT-OH - with dimethylcarbonate using TBD as catalyst. The network is then able to bond and debond on demand due to the HDA units within minutes as a function of the applied temperature. 


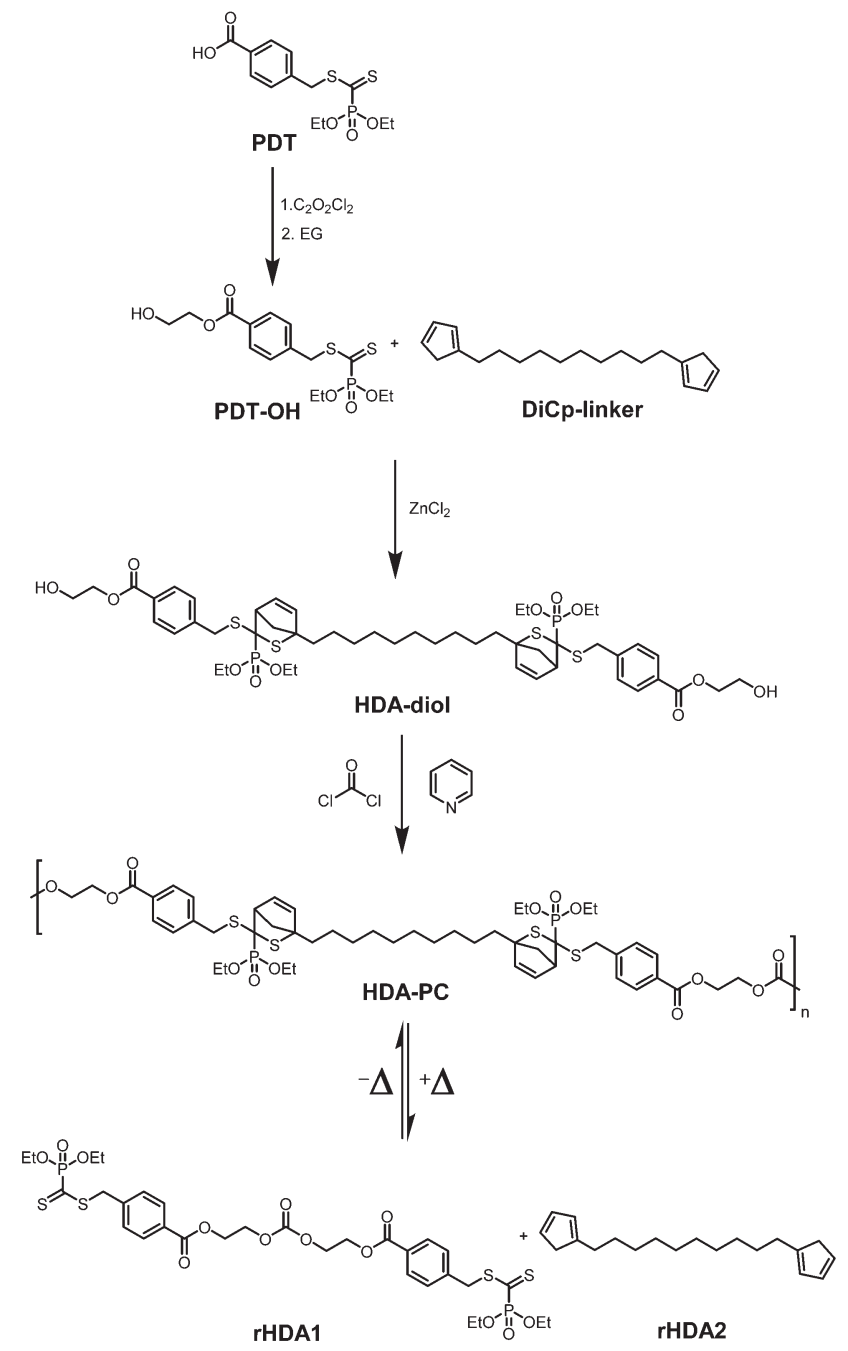

Scheme 2 Synthetic strategy for the formation of linear polycarbonates bearing HDA moieties in the backbone (HDA-PC), as well as the products of the rHDA reaction (rHDA1 and rHDA2). relatively mild conditions, a phosphoryl dithioester (PDT) and a dicyclopentadiene-linker (DiCp-linker) were used as diene and dienophile. The employed HDA-pair has proven to be an excellent choice as earlier studies revealed that it can cleave and reform within minutes at temperatures between 30 and $140{ }^{\circ} \mathrm{C}$, depending on the degree of debonding. ${ }^{8,27}$ As the HDA pair starts to cleave at close to $30{ }^{\circ} \mathrm{C}$, a step-growth polymerization had to be employed that can be conducted at ambient temperatures. Therefore, polycarbonates were formed based on the reaction of an alcohol - bearing the HDA moieties - with either phosgene or dimethyl carbonate (HDA-PC).

\section{Linear polycarbonates (HDA-PC)}

To analyze the reversibility, linear polycarbonates (HDA-PC) were formed in an initial step. The synthetic strategy is depicted in Scheme 2. PDT and the DiCp-linker were synthesized according to a previous publication. ${ }^{27}$ The PDT was subsequently esterified in order to obtain an alcohol by using an in situ formation of the carbonyl chloride with oxalyl chloride, followed by an esterification reaction using ethylene glycol (PDT-OH). To obtain a polymerizable diol (HDA-diol), the PDT-OH and the DiCp-linker were reacted in a HDA reaction using zinc chloride as catalyst. The polymerizations were then carried out by employing the prepared HDA-diol and a phosgene solution under pyridine catalysis at ambient temperature. Next, the polymers were readily purified via precipitation in hexane.

As can be seen in Fig. 1a, different weight-average molecular weights $\left(M_{\mathrm{w}}\right)$ can be obtained for the HDA-PC's ranging from 4.200 to $20.000 \mathrm{~g} \mathrm{~mol}^{-1}$ by varying the composition of the monomer mixtures. In order to evidence the reversibility of the invented system, the degradation upon heating had to be studied first. Therefore, $\mathbf{P 4}$ was dissolved in DMF and heated to different temperatures $\left(60,100,140{ }^{\circ} \mathrm{C}\right)$. After stirring for 3 minutes at the desired temperature, the solvent was evaporated and the residual was taken up in THF and analyzed via
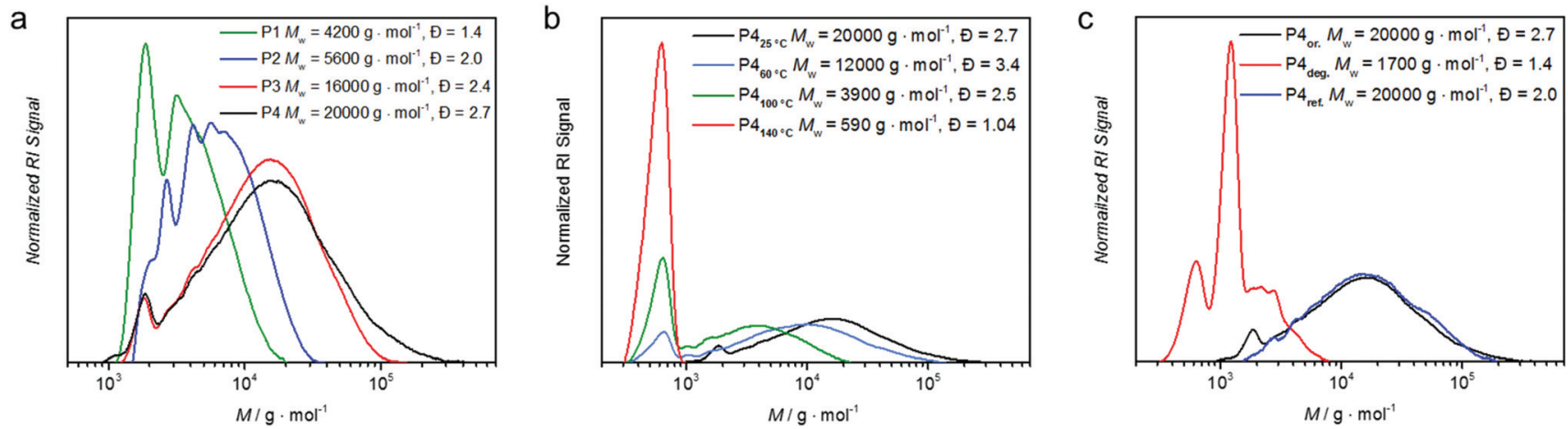

Fig. 1 Analysis of the bonding/debonding behavior of the HDA-containing linear polycarbonates. (a) SEC analysis of polycarbonates P1-P4 with different degrees of polymerization. (b) SEC analysis of P4 at 25, 60, 100 and $140^{\circ} \mathrm{C}$. (c) SEC analysis of the bonding/debonding behavior of P4 upon heating and cooling. $\mathbf{P} 4_{\text {or }}$ is the original P4 polymer, $\mathbf{P} 4_{\text {deg. }}$. the degraded polymer at $120{ }^{\circ} \mathrm{C}$ and $\mathbf{P} 4_{\text {ref. }}$ the reformed polymer upon cooling. Solvent: THF. 
SEC. In Fig. 1b the degradation of $\mathbf{P 4}$ with increasing temperature is clearly visible, as the molecular weight decreases from $20.000 \mathrm{~g} \mathrm{~mol}^{-1}$ at $25{ }^{\circ} \mathrm{C}$ to $590 \mathrm{~g} \mathrm{~mol}^{-1}$ at $140{ }^{\circ} \mathrm{C}$.

In a final step, the reversibility had to be established. Therefore, SEC analysis, UV/Vis and HT-NMR spectroscopy of $\mathbf{P 4}$ were carried out. For SEC analysis, a solution of $\mathbf{P 4}$ in DMF was heated to $120^{\circ} \mathrm{C}$ and a sample was taken and analyzed via SEC. The remaining solution was cooled to ambient temperature. After removal of the solvent, SEC analysis revealed that the degradation is fully reversible since the same molecular weight could be obtained as for the initial polymer (see Fig. 1c). In addition, UV/Vis spectroscopy was carried out to demonstrate the reversibility. Therefore, $\mathbf{P 4}$ was dissolved in DMF and the solution was employed in three heating and cooling cycles from 20 to $100{ }^{\circ} \mathrm{C}$ (upper limit of the instrument) with a heating/cooling rate of $5{ }^{\circ} \mathrm{C} \mathrm{min}^{-1}$. Since a purple dithioester species (rHDA1) is formed upon heating, the analysis was conducted at $530 \mathrm{~nm}$. As can be seen in Fig. 2a, the polymer can be cleaved and rebonded several times. Moreover, HT-NMR spectroscopic studies were conducted to prove the reversibility on a molecular level. Hence, P4 was dissolved in DMSO- $d_{6}$ and analyzed at different temperatures. As Fig. 2b reveals, the formation of the DiCp-linker upon heating to $110^{\circ} \mathrm{C}$ can be evidenced based on the resonance between 6.4-6.5 ppm $\left(\mathrm{H}_{\mathrm{a}}\right)$. When the sample is cooled to $25^{\circ} \mathrm{C}$ the HDA moiety rebonds, which is indicated by the reformation of the resonances between 5.6-5.85 $\mathrm{ppm}\left(\mathrm{H}_{\mathrm{b}}\right)$.

\section{Polycarbonate networks}

As the bonding/debonding on demand behavior of the linear polycarbonates could be established, a polycarbonate network was formed in a final step. As depicted in Scheme 3, a triol species (HDA-triol) was synthesized in order to achieve network formation. In a first step, a core bearing three cyclopentadiene units had to be prepared. Therefore, 1,3,5-benzene-
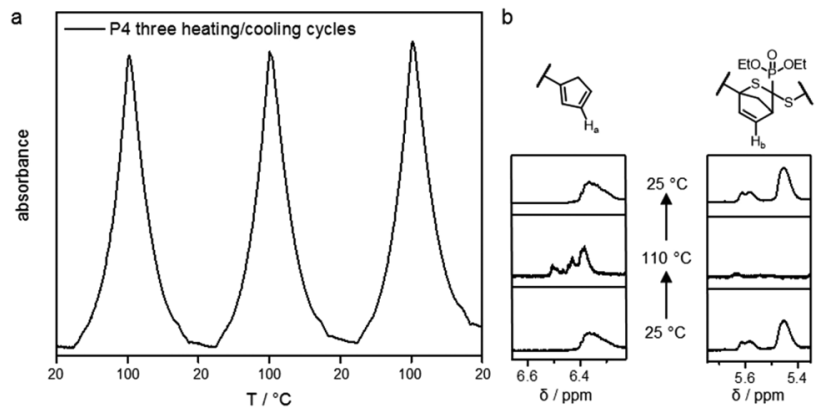

Fig. 2 (a) UV/Vis analysis of the bonding/debonding behavior of the polymer P4 at $530 \mathrm{~nm}$ from 20 to $100{ }^{\circ} \mathrm{C}$ with a heating/cooling rate of $5{ }^{\circ} \mathrm{C} \mathrm{min}^{-1}$. (b) ${ }^{1} \mathrm{H}$ NMR spectra of the bonding/debonding behavior of the prepared linear polycarbonates using the HDA-diol and phosgene. The resonance of the cyclopentadienyl moiety is depicted on the left side (6.5-6.4 ppm, $\mathrm{H}_{\mathrm{a}}$ ) and the resonance associated with the HDA reaction product is shown on the right side (5.85-5.6 ppm, $\left.\mathrm{H}_{\mathrm{b}}\right)$. After heating to $110{ }^{\circ} \mathrm{C}$ for 5 min (cleavage), $\mathrm{P} 4$ is reformed upon cooling to $25^{\circ} \mathrm{C}$ (instant measurement after temperature is reached).<smiles>O=C(Cl)c1cc(C(=O)Cl)cc(C(=O)OCCCBr)c1</smiles>

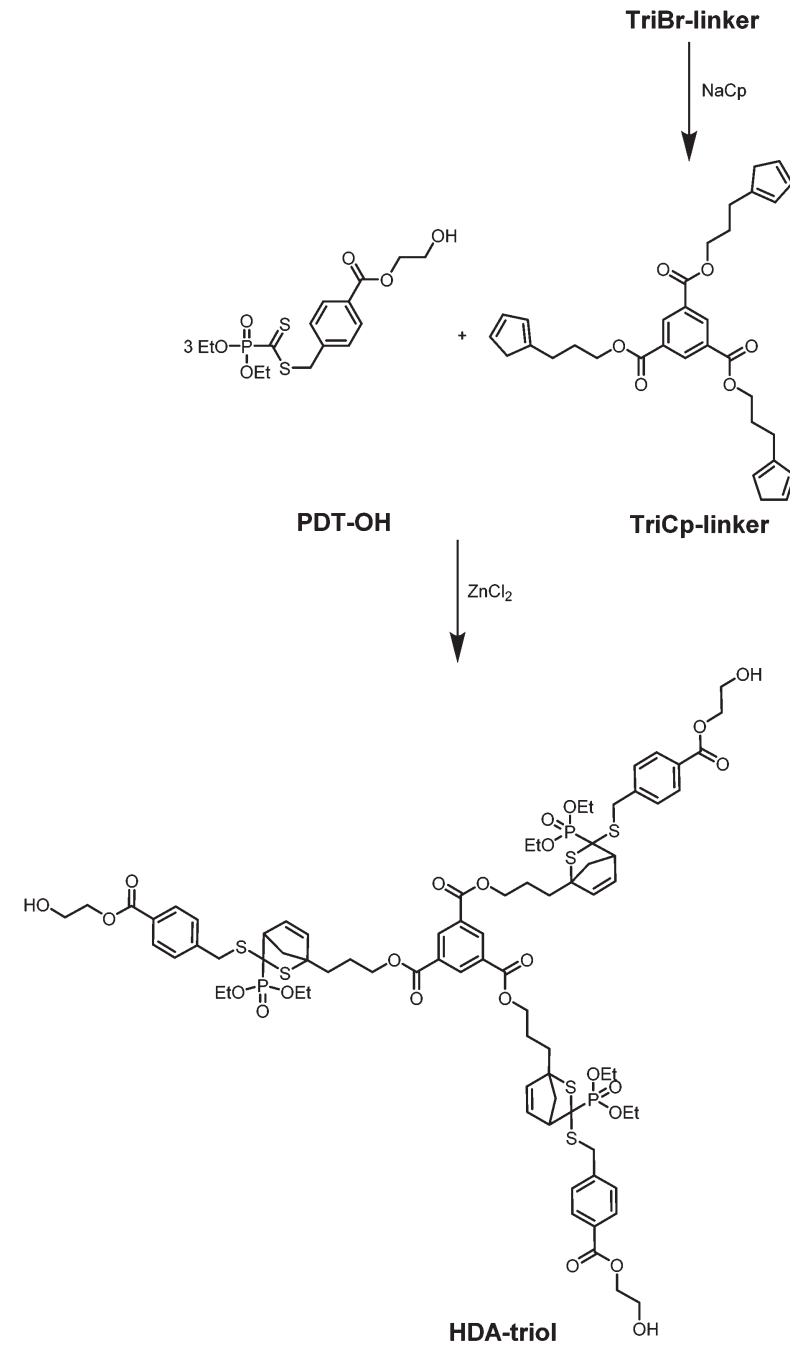

Scheme 3 Synthetic protocol for preparation of an HDA-containing triol (HDA-triol).

tricarbonyl chloride was esterified with 3-bromo-1-propanol, followed by a substitution reaction using $\mathrm{NaCp}$ to yield the desired core (TriCp-linker). In order to prevent reactions between the $\mathrm{Cp}$ moieties, the linker was directly employed in a HDA reaction with the PDT-OH to form the stable HDA-triol.

As network formation using a phosgene solution and pyridine (excess) would lead to an incorporation of the pyridinium salt into the network decreasing its stability, a different strategy compared to the linear polycarbonate formation was followed. Dimethyl carbonate was the reactant of choice, as it is able to undergo polycarbonate formation using catalytic 

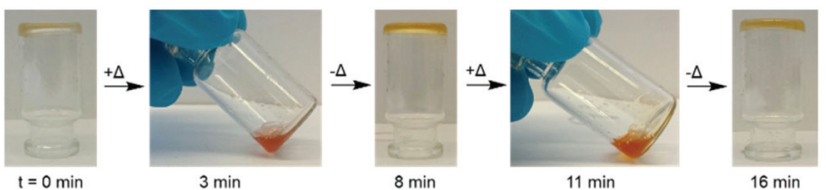

Fig. 3 Bonding/debonding behavior of the prepared HDA-containing polycarbonate network $\left(+\Delta\right.$ : heating to $120^{\circ} \mathrm{C},-\Delta$ : cooling to $\left.25^{\circ} \mathrm{C}\right)$. Heating was conducted with a preheated oil bath and a water bath was used for cooling. The time indicates the minute, at which the picture was taken. The red color upon heating is due to the formation of a dithioester species (rHDA1).

amounts of TBD, yielding only methanol as byproduct, which can readily be removed via evaporation. Moreover, it is a green and environmentally friendly alternative to the highly toxic phosgene. As can be seen in Fig. 3, a polycarbonate network could be obtained using the HDA-triol and dimethyl carbonate under TBD catalysis. When the formed network is heated to $120{ }^{\circ} \mathrm{C}$, a drastic decrease in mechanic stability (solid to liquid) as well as a coloration becomes visible, which indicates the formation of the dithioester species (rHDA1). Moreover, the network reforms upon cooling within minutes. Three degradation and rebonding cycles were conducted, clearly proving the reversibility of the invented system.

\section{Conclusions}

An in-depth study of a novel bonding/debonding on demand polymer network based on a step-growth polymerization, featuring HDA moieties, is presented. The employed HDA system is known to undergo bonding and debonding at temperatures between 30 and $120^{\circ} \mathrm{C}$ within minutes. As linear polymers can be investigated in more detail with regard to their molecular changes than polymer networks, linear polycarbonates for bonding/debonding tests were prepared in an initial step. Therefore, a new HDA containing diol was synthesized and reacted with phosgene (in solution) to form linear polycarbonates. In depth studies of the polymers via SEC analysis, UV/ Vis and high temperature ${ }^{1} \mathrm{H}$ NMR spectroscopy demonstrate the degradability as well as the reversibility of the invented system. In order to prepare a network, a new triol bearing three HDA moieties was synthesized. The triol was then reacted with dimethyl carbonate, which is a more environmentally friendly alternative to phosgene, to form the desired stepgrowth based network. Three heating and cooling cycles were conducted, demonstrating the rapid bonding/debonding on demand properties of the invented system, as the solid network turns into a red liquid upon heating, yet is reformed when cooled to ambient temperature within minutes.

\section{Acknowledgements}

C. B.-K. acknowledges funding from and the excellent collaboration with Ivoclar Vivadent AG as well as continued funding from the Karlsruhe Institute of Technology (KIT) in the context of the Helmholtz BIFTM and STN programs.

\section{Notes and references}

1 C. J. Kloxin, T. F. Scott, B. J. Adzima and C. N. Bowman, Macromolecules, 2010, 43, 2643-2653.

2 J. Zhou and S. S. Sheiko, J. Polym. Sci., Part B: Polym. Phys., 2016, 54, 1365-1380.

3 Z. Liu, W. Wang, R. Xie, X.-J. Ju and L.-Y. Chu, Chem. Soc. Rev., 2016, 45, 460-475.

4 S. Guragain, B. P. Bastakoti, V. Malgras, K. Nakashima and Y. Yamauchi, Chem. - Eur. J., 2015, 21, 13164-13174.

5 K. Sumaru, M. Kameda, T. Kanamori and T. Shinbo, Macromolecules, 2004, 37, 4949-4955.

6 E. Cabane, V. Malinova and W. Meier, Macromol. Chem. Phys., 2010, 211, 1847-1856.

7 Q. Yan, D. Han and Y. Zhao, Polym. Chem., 2013, 4, 50265037.

8 M. Langer, J. Brandt, A. Lederer, A. S. Goldmann, F. H. Schacher and C. Barner-Kowollik, Polym. Chem., 2014, 5, 5330-5338.

9 A. F. Hirschbiel, B. V. K. J. Schmidt, P. Krolla-Sidenstein, J. P. Blinco and C. Barner-Kowollik, Macromolecules, 2015, 48, 4410-4420.

10 J. E. Stumpel, E. R. Gil, A. B. Spoelstra, C. W. M. Bastiaansen, D. J. Broer and A. P. H. J. Schenning, Adv. Funct. Mater., 2015, 25, 3314-3320.

11 I.-K. Park, K. Singha, R. B. Arote, Y.-J. Choi, W. J. Kim and C.-S. Cho, Macromol. Rapid Commun., 2010, 31, 1122-1133.

12 J. J. Gallagher, M. A. Hillmyer and T. M. Reineke, Macromolecules, 2014, 47, 498-505.

13 E. Themistou and C. S. Patrickios, Macromolecules, 2007, 40, 5231-5234.

14 R. R. De Clercq and E. J. Goethals, Macromolecules, 1992, 25, 1109-1113.

15 K. K. Oehlenschlaeger, N. K. Guimard, J. Brandt, J. O. Mueller, C. Y. Lin, S. Hilf, A. Lederer, M. L. Coote, F. G. Schmidt and C. Barner-Kowollik, Polym. Chem., 2013, 4, 4348-4355.

16 Y. Chen and K.-H. Chen, J. Polym. Sci., Part A: Polym. Chem., 1997, 35, 613-624.

17 J. W. Kamplain and C. W. Bielawski, Chem. Commun., 2006, 1727-1729, DOI: 10.1039/B518246H.

18 Y. Furusho, T. Oku, T. Hasegawa, A. Tsuboi, N. Kihara and T. Takata, Chem. - Eur. J., 2003, 9, 2895-2903.

19 E. Themistou and C. S. Patrickios, Macromolecules, 2006, 39, 73-80.

20 X. Chen, M. A. Dam, K. Ono, A. Mal, H. Shen, S. R. Nutt, K. Sheran and F. Wudl, Science, 2002, 295, 1698-1702.

21 A. Gandini, A. J. D. Silvestre and D. Coelho, J. Polym. Sci., Part A: Polym. Chem., 2010, 48, 2053-2056.

22 E. Goiti, F. Heatley, M. B. Huglin and J. M. Rego, Eur. Polym. J., 2004, 40, 1451-1460.

23 J. R. Jones, C. L. Liotta, D. M. Collard and D. A. Schiraldi, Macromolecules, 1999, 32, 5786-5792. 
24 M. Reinecke and H. Ritter, Makromol. Chem., 1993, 194, 2385-2393.

25 N. K. Guimard, J. Ho, J. Brandt, C. Y. Lin, M. Namazian, J. O. Mueller, K. K. Oehlenschlaeger, S. Hilf, A. Lederer, F. G. Schmidt, M. L. Coote and C. Barner-Kowollik, Chem. Sci., 2013, 4, 2752-2759.

26 K. Pahnke, J. Brandt, G. Gryn'ova, P. Lindner, R. Schweins, F. G. Schmidt, A. Lederer, M. L. Coote and C. BarnerKowollik, Chem. Sci., 2015, 6, 1061-1074.

27 A. M. Schenzel, C. Klein, K. Rist, N. Moszner and C. Barner-Kowollik, Adv. Sci., 2016, 3, 1500361.

28 K. K. Oehlenschlaeger, J. O. Mueller, J. Brandt, S. Hilf, A. Lederer, M. Wilhelm, R. Graf, M. L. Coote, F. G. Schmidt and C. Barner-Kowollik, Adv. Mater., 2014, 26, 3561-3566.
29 http://www.mcgroup.co.uk, (accessed 06.10., 2016).

30 M. Xie, L. Yu, Z. Li, Z. Zheng and X. Wang, J. Polym. Sci., Part A: Polym. Chem., 2016, 54, 3583-3592.

31 M. N. Ganivada, P. Kumar, P. Kanjilal, H. Dinda, J. D. Sarma and R. Shunmugam, Polym. Chem., 2016, 7, 4237-4245.

32 J.-Y. Fang, Y.-K. Lin, S.-W. Wang, Y.-C. Li and R.-S. Lee, React. Funct. Polym., 2015, 95, 46-54.

33 W. Thongsomboon, M. Sherwood, N. Arellano and A. Nelson, ACS Macro Lett., 2013, 2, 19-22.

34 B. N. Jang and C. A. Wilkie, Thermochim. Acta, 2005, 426, 73-84.

35 http://www.ampolymer.com/Mark-HouwinkParameters.html, (accessed 10.09., 2016). 